\title{
Outgroup Trust, Boundary Spanning and Leaders' Successes among Small Private Firms --- A Cross-National Study
}

\author{
W. X. JIANG ${ }^{1, a}$, Chang LIU ${ }^{2, b, *}, J_{i} L^{3, c}$ \\ ${ }^{1}$ Department of Management, School of Business, Hong Kong Baptist University, Kowloon Tong, HK \\ ${ }^{2}$ Department of Economics, Chang Chun School of Administration, Chang Chun, China \\ ${ }^{3}$ Department of Management, School of Business, Hong Kong Baptist University, Kowloon Tong,Hong \\ Kong, China \\ aE-mail: 14484919@life.hkbu.edu.hk \\ bPhone: (189) 4308-1577,E-mail: Liuchang9098@gmail.com \\ 'Phone: (852) 3411-7562,Fax: (852) 3411-5583,E-mail: jili@hkbu.edu.hk \\ ${ }^{*}$ Corresponding author: Chang Liu
}

Key words: Boundary spanning, Outgroup trust and leaders' success.

\begin{abstract}
We extend the research of outgroup trust to boundary spanning and leaders' successes in small business firms of 35 countries. Using the technique of HLM analysis, we found that leaders of the small firms should be more likely to engage in boundary spanning if their outgroup trust is high. On the other hand, their boundary spanning can have positive effects on two dimensions of their career success, i.e., their success in terms of social status and that of personal income. Finally, the relationship between outgroup trust and boundary spanning can be stronger in societies with individualistic cultural values than in those with collectivistic ones.
\end{abstract}

\section{Outgroup Trust, Boundary Spanning and Leaders' Successes among Small Private Firms: Does Societal Culture Matter?}

Both outgroup trust and boundary spanning have important implications for managerial and business successes, especially in environments with demographic diversities (e.g., Muethel and Bond, 2013; $\mathrm{Li}$ and Khatri, 1999). On the one hand, outgroup trust can defined as a personal value/behavior that involves the confidences in a wider circle of unfamiliar others (e.g., Muethel and Bond, 2013; Delhey, Newton and Welzel, 2011; Luo, 2005). This type of trust has been suggested to be a crucial driver of success in profit-oriented firms (Muethel and Bond, 2013).

On the other hand, according to the literature (e.g., Kramer, 1991; Flynn, Chatman and Spataro, 2001), boundary spanning can be defined as an action/strategy performed by members in a given group/organization that involves active communications and interactions with unfamiliar others who are from outgroups/ outorganizations. This strategy has been suggested to affect a person's organizational identity and identification (Bartel, 2001) as well as her/his impressions of members from outgroups (Flynn, Chatman and Spataro, 2001). On the issue of leadership effectiveness, this strategy has been shown to help leaders to bind their community together (Perrone, Zaheer and McEvily, 2003)

In spite of the arguments, the actual effects of outgroup trust on firm leaders' behavior or strategy, such as their boundary spanning, have not been tested empirically. For instance, although some authors have studied the relationships among trust, boundary spanning, and leadership (e.g., Fleming and Waguespack, 2007), the sample they used in the study was internet users in open innovation communities, which, as the authors admitted, were different from the profit-oriented private firms (Page 176). In other words, the open innovation communities are not profit-oriented, and their organization structure, include those dimensions as power distribution and decision-making, is totally different from that of profit-oriented private firms. As a result, it remains unclear the relationship among outgroup trust, boundary spanning and the leaders success among the private firms. 
Moreover, research also suggests that outgroup trust may be influenced by societal culture (e.g., Muethel and Bond, 2013), yet it remains unclear whether the culture can affect the relationship between outgroup trust and a leader's success.

In this paper, we contribute to the literature by developing a contingency model showing how societal culture may moderate the relationship between outgroup trust and boundary spanning among small private firms, and how this boundary spanning leads to greater success of the leaders in these profit-oriented firms (see Figure 1). Moreover, we predict that the relationship between outgroup trust and boundary spanning can be moderated by societal culture.

\section{Literature Review}

\section{Outgroup Trust and Boundary Spanning}

Research has identified two types of trust (e.g., Delhey, Newton and Welzel, 2011): the in group trust and outgroup one. According to the literature, we can define ingroup trust as a personal value/behavior that covers the confidences in a narrow circle of familiar others, such as family, neighbors, and people known personally (e.g., Delhey, Newton and Welzel,2011). Some authors also called ingroup trust "particularistic trust" (Luo, 2005; Xin \& Pearce, 1996), which is argued to have significant effects in small communities where social interactions are intensive, social controls are strong, and misbehavior can be sanctioned (Gambetta, 1988; Yamagishi, Lin, \& Miller, 1998b).

On the other hand, we can define outgroup trust as a personal value/behavior that covers the confidences in a wider circle of unfamiliar others (Delhey, Newton and Welzel, 2011; Luo, 2005). Outgroup trust is more likely to have a significant effect on a person's decision and behaviors when this person meets unfamiliar others, such as those unfamiliar ones from different religions and nationalities (e.g., Delhey, Newton and Welzel, 2011). Outgroup trust may improve communication and interactions between them (Luo, 2005).

It is worth pointing out that, according to research, outgroup trust does not have negative effects on other types of trust.For instance, Bahry (2005) found a positive correlation between ingroup and outgroup trust and concluded that trust in ingroups and that in outgroups are not mutually exclusive, but complementary. Glanville and Paxton (2007) also showed that there is no evidence that trust in any one domain (particular trust) hinders the development of general trust.

For small private firms that often have insufficient resources, especially at the early stage of their business, outgroup trust should be helpful because it encourages the leaders of these firms to increase their community boundary spanning so that they can have better communication and interactions with unfamiliar others (e.g., Muethel and Bond, 2013). Through these communications and interactions, the leaders are more likely to obtain new resources and improve their performance. We will provide some further discussion on this issue later in this paper.

There has been no empirical research directly testing the relationship between outgroups trust and boundary spanning. However, based on research findings, it is arguable the outgroup trust should have a positive effect on the leaders' boundary spanning. Specifically, outgroup trust encourages friendly and positive communications and interactions between a given leader and his/her outgroup others, which can have a psychological effect that helps to overcome the sense of uncertainty in knowing new parties or new people (e.g., Kollock, 1994). As a result, outgroup trust can lead to a positive bias in the processing of imperfect information when making decisions for a leader's boundary spanning (Yamagishi \& Yamagishi, 1994). In other words, outgroup trust can lead to more "boundaryspanning and uncertainty-absorption behaviors identified through ethnographic epistemological foundations” (Muethel and Bond, 2013). Accordingly, we predict,

\section{Hypothesis 1}

Among leaders of small private firms, there is a positive relationship between their outgroup trust and their boundary spanning. 


\section{The Moderating Effect of Societal Cultures on the Relationship between Outgroup Trust and Boundary Spanning}

Societal culture can be considered an important part of social institutions (Scott, 2001; Dacin, Goodstein, \& Scott, 2002).According to institutional theory, institutional elements, including societal culture, influence the interpretation of issues or actions as they emerge and persist (Scott, 2001). Accordingly, societal culture can also influence the definition of organizational boundary and the application of boundary spanning. Here societal culture should include social and cultural meaning systems, or norms, that are taken for granted and that define social reality (DiMaggio, 1988; Scott, 2001). These norms are the "rules of procedures that actors employ flexibly and reflexively to assure themselves and those around them that their behavior is reasonable" (DiMaggio \& Powell, 1991: 20), and which act as unwritten rules of proper social or organizational conduct to which organizations or individuals must adhere. Institutional theory suggests that both organizational and individual activities must reflect the norms of their institutional environments, and that therefore rather than being the result of a rational strategic purpose, organizations are "constructed as legitimate agents of great collective purposes, from technical rationality and social progress, to social integration and justice” (Meyer \& Scott, 1992: 1).

In studying institutional systems, Scott (1995) considered societal culture as the cognitive-cultural aspect of social institutions, which embodies symbols, words, signs, gestures, and the cultural rules and frameworks that guide the understanding of the nature of reality and the frames through which that meaning is developed (Scott, 2001). Organizations will often abide by them without conscious thought (Zucker, 1983). As a result, elements of this institution aspect form a culturally supported and conceptually correct basis of legitimacy that becomes unquestioned (Hoffman, 1999; Li, Lam, Sun and Liu, 2008).

Among the cognitive-cultural institutional elements or different aspects of societal culture, the societal value of individualism/collectivism (hereafter IDV) is perhaps the most useful and powerful dimension of societal culture in explaining a diverse array of social behaviors (Triandis, 1995). In a given society, this dimension of culture embodies important symbols, words, signs, gestures, cultural rules and frameworks that should influence individual and organizational behaviors. Despite being conducted widely at different times, with different samples and methods, major studies of national variation in cultural values (e.g., Hofstede, 1980; Schwartz, 1994; House et al., 2004) have identified this dimension of societal culture. This convergence suggests that IDV is a broad and comprehensive cultural value which helps distinguish between major societal cultures globally. In addition, the value of IDV may be particularly relevant to the relationship between outgroup trust and boundary spanning being studied in our current paper. The reason is that, according to research, the value of IDV may moderate the relationship between outgroup trust and its consequences (e.g.,Gomez, Kirkman\& Shapiro, 2000). Finally, according to relevant empirical evidence, the societal cultural value of IDV is strongly correlated with other commonly-tested cultural values, such as power distance (Hofstede, 1980).

According to the literature, individualism/collectivism (IDV) can be defined as the degree to which people look after their own interests as opposed to the interests of ingroups and outgroups (Hofstede, 1980). As a major cultural value at the societal level, IDV may moderate the relationship between outgroup trust and boundary spanning. In a collectivistic culture/institutional environment, for instance, a person is more likely to feel strongly about belonging to a certain social category, i.e., such as a family or a clan (Sanyal, 2009; van Stekelenburg, Boekkooi, van Stekelenburg, Roggeband, \&Klandermans, 2013). This sense of belonging may have be conflicting with that of outgroup trust. Given the same level of outgroup trust, a person from collectivistic societies may prefer to interact and communicate mainly with those from her/his family or clan mainly (Li and Khatri, 1999), and ignore those outgroup members.

Moreover, in a collectivistic society, the community boundary spanning of a given person is more likely to be influenced by family or clan related variables, such as kinship (Li and Khatri, 1999), in addition to outgroup trust. In other words, the direct relationship between outgroup trust and boundary spanning may be weakened in a collectivistic institutional environment because the 
boundary spanning can be influenced by the family or clan-related variables regardless of outgroup trust. On the other hand, in an individualistic institutional environment, one's motivation for community boundary spanning is more likely to be influenced by her/his own value, feeling and trust regardless of family or clan-related variables. In this case, individual outgroup trust is more likely to predict individual motivation for boundary spanning directly.

Taking together, the relationship between outgroup trust and the boundary spanning in the collectivistic institutional environment should be weaker than that in an individualistic institutional environment. Therefore, we predict,

\section{Hypothesis 2}

The individualistic societal culture moderates the relationship between outgroup trust and boundary spanning. Other conditions being equal, the higher the individualistic value in a society, the stronger the positive relationship between outgroup trust and boundary spanning.

\section{Method}

\section{Sample and Data}

Our data came from two sources: the World Values Survey (http://www.worldvaluessurvey.org/wvs.jsp) and the study on societal cultural values by Hofstede (1980, 2001). The World Values Survey grew out of a 24-country study originally launched by the European Values Survey (EVS) in 1981 under the leadership of Jan Kerkhofs and Ruud de Moor (Inglehart, Basanez, \& Moreno, 1998). Between 1981 and 2004, respondents from more than 50 nations/societies were interviewed by researchers in the project of the World Values Survey (WVS). Among these subjects, there were 5451 small firm leaders from 35 countries (see Table 1). They provided data on their individual-level outgroup trust, community boundary spanning, and their self-perceived social and income status. These individual-level data, as mentioned above, were matched with Hofstede's data of societal-level culture - Individualism/collectivism (Hofstede, 1980, 2001). We use this dimension of societal culture as a proxy of societal culture.

\section{Measures}

Leaders' success was measured from two aspects-- success in terms of financial income and that in terms of social status. We measured both of them with data from WVS (Source: European and World Values Surveys four-wave integrated data file, 1981-2004, v.20060423). Specifically, financial success was measured by a scale of incomes (1= lowest income, $10=$ highest income). Success in terms of social status was tested by another scale testing a subject's self-perceived social class in her/his country (1=lowest class, $2=$ =low class, $3=$ =lower middle class, 4=upper middle class, and 5=upper class). Although these two dimensions of success can be correlated, we consider it helpful to study them as two different dimensions of leaders' success because high social status does not always mean high income.

Outgroup Trust. Consistent with prior research (e.g. Delhey et al.2011), this trust was measured with a 3-item scale from WVS (1= not trust at all; $5=$ trust completely): 1 ) the degree to which you trust people that you meet for the first time, 2) the degree to which you trust people of another religion, and 3) the degree to which you trust people of another nationality. This 3-item scale shows diversified aspects of outgroup trust and demonstrates good reliability $(\alpha=0.81)$.

Community Boundary Spanning. This variable was measured with a 8-item scale from WVS, which assesses whether a subject is a member of such an organization as 1) "church or religious organization”, 2) "sport or recreation one”, 3) “art, music, educational one”, 4) "labour unions”, 5) “political party”, 6)“environmental organization”,7) “professional organization”, and 8) "charitable/humanitarian organization" ( $0=$ not a member; $1=$ inactive member; $2=$ active member). The reliability alpha of the scale is 0.78 .

Societal Culture. This variable was measured by the societal value of IDV based on the data from Hofstede (2001). As mentioned above, this piece of data is available from a web site (Source: 
http://geert-hofstede.com/countries.html). Higher score in a country/society means higher level of individualistic societal culture.

\section{Hierarchical Linear Modeling}

The method of Hierarchical linear modeling (HLM) was adopted to investigate the effects of outgroup trust, societal-level cultural value - individualistic value, and their joint effects on a leader's community boundary spanning. The reason for using this method is that our data were multi-level ones with individual variables, such as demographic variables (age, gender) and outgroup trust (Level 1), nested within societal culture measurement at the societal level (Level 2). To analyze data with this character, the primary analytical technique should be HLM (Bryk \&Raudenbush, 1992; Hofmann, 1997).In other words, HLM is particularly well suited for estimating the type of cross-level interactions between individual-level variables on the one hand and social-level variables such as the measure of societal culture on the other hand.

With the method of HLM, we first tested Hypothesis1 by controlling the influence from societal-level values (societal culture). In the first step, we entered the dependent variable and control variables (Model 1). After that, we entered the independent variable, i.e., outgroup (Model 2).Finally, we tested the moderating effect of societal culture as a societal level variable (Model 3 and 4).

Table 1 shows the results of the analysis. The result of Model 2 in Table 3 shows that hypothesis 1 is supported. In other words, a significant and positive relationship exists between outgroup trust and the leaders' community spanning $(\beta=0.27, \mathrm{p}<0.005)$. Also, with the entry of the data on societal-level institution in Model 3 and Model 4, the significant relationship between outgroup trust and boundary spanning remains consistent (Model 3 \& 4, Table 3). Finally, there exists a significantly positive effect of IDV on the relationship between outgroup trust and the boundary spanning, which mirrors Hypothesis2. As the data suggest, the higher the societal culture of individualism, the stronger the

\section{Discussion and Implications}

The results of our current research, as reported above, support a positive effect of outgroup trust on the leaders' boundary spanning, which in turn has positive effects on the leaders' successes socially and economically. Considering the results, one can see a number of important contributions of our current research to the management research literature.

First of all, our current study is the first one testing the relationship between outgroups trust and the boundary spanning empirically. Although some authors have suggested its importance (Muethel and Bond, 2013), the empirical evidence on the relationship between outgroup trust and boundary spanning has not been documented so far. Our current research bridges this gap by showing a positive relationship between outgroup trust and boundary spanning. As our result suggest, outgroup trust can have a positive relationship with the boundary spanning of small firm leaders, which in turn can help improve the possibility of Leaders' successes. In other words, our findings suggest that the inter-firm relationships between a given small firm leader and its outside supply of resources may be improved by constructive communications and interactions with unfamiliar others in its community based on outgroup trust. One major reason here can be that, as mentioned above, outgroup trust may help improving the understanding between the parties and reducing transaction-costs in boundary spanning, such as the cost of examining and monitoring the behaviors of those unfamiliar others. This boundary spanning, in turn, can help improving the effectiveness of small firm leaders and help the leaders to be more successful.

Next, our current research tests the moderating effect of societal culture on the relationship between outgroup trust and boundary spanning. Our findings suggest that, in an environment with individualistic societal culture, outgroup trust may be more effective because it is more likely to improve mutual cooperation (Zaheer, McEvily, \& Perrone, 1998) and reducing uncertainty about outside parties or partner behavior (Krishnan, Martin, \& Noorderhaven, 2006). In other words, 
outgroup trust is more likely to improve a leader's boundary spanning in an institutional environment with a high level of individualism.

Table 1. Results of hierarchical linear modeling analysis and hierarchical regression analysis

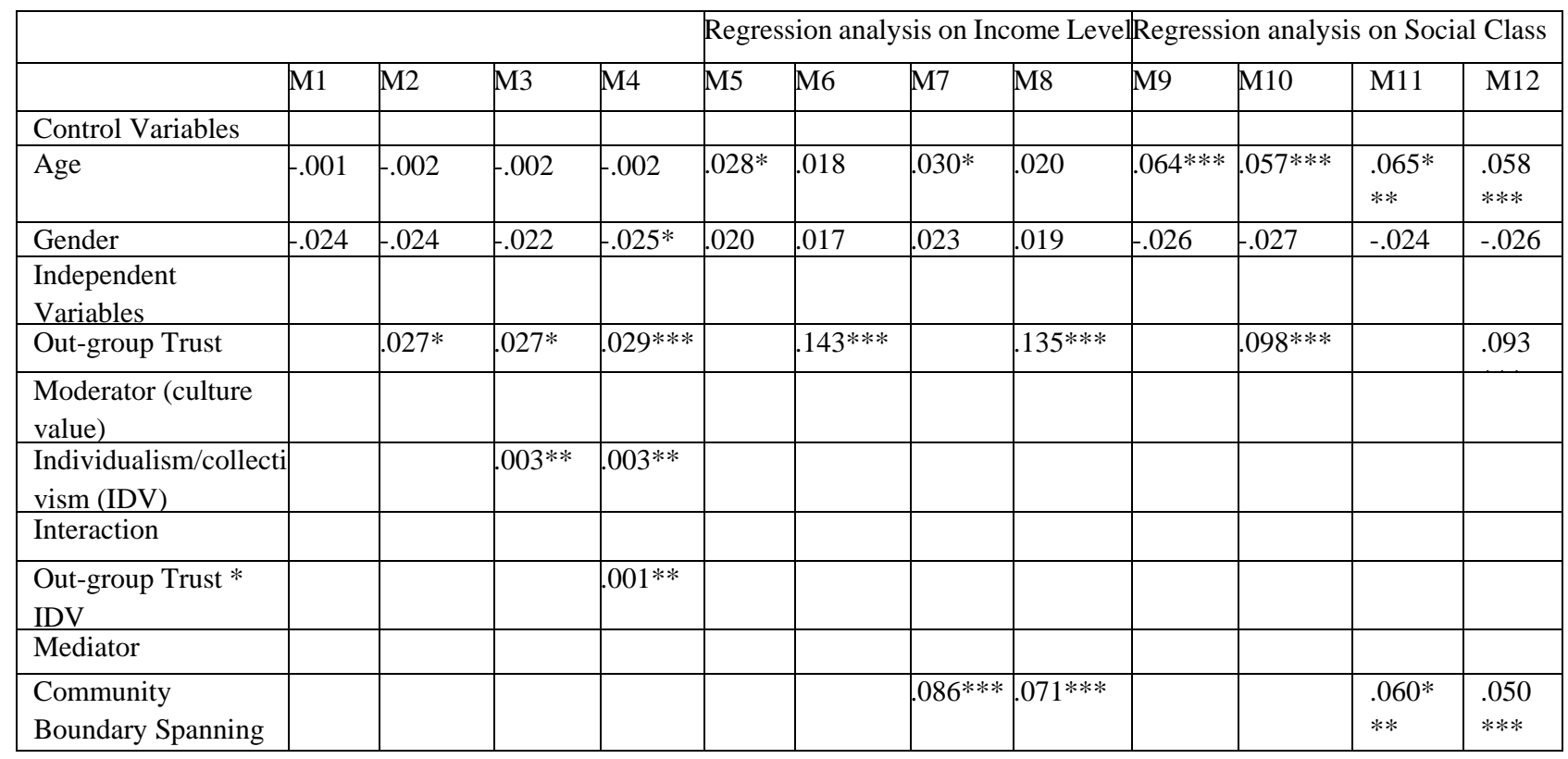

Note: *p0.05; **p.01; ***p0.001; N=35 nations; Respondents=5451.

\section{Conclusion}

Taken together, the findings of our current study allow us to have several conclusions. A) Outgroup trust can help enlarge leaders' boundary spanning, at least among leaders of small private firms. B) Societal culture of IDV moderates the relationship between outgroup trust and boundary spanning. In a cultural environment with a high level of individualistic values, the effect of outgroup trust on boundary spanning can be more significant than that with collectivistic ones. C) Finally, boundary spanning has a positive effect on the leaders' success on both the dimension of income and that of social status. All these findings, as mentioned above, can have important implications for academic researchers and managerial practitioners.

\section{References}

[1] Judge, T. A., Klinger, R. L., \& Simon, L. S. (2010). Time is on my side: time, general mental ability, human capital, and extrinsic career success. Journal of Applied Psychology, 95(1), 92.

[2] Lau, V. P., Shaffer, M. A., \& Au, K. (2007). Entrepreneurial career success from a Chinese perspective: conceptualization, operationalization, and validation. Journal of International Business Studies, 38(1), 126-146.

[3] Bryk, A., \& Raudenbush, S. 1992. Hierarchical linear models for social and behavioral research. In Applications and Data Analysis Methods, Sage Publications, Inc., London, UK.

[4] Kenny, D. A., Kashy, D. A., \& Bolger, N. (1998). Data analysis in social psychology. In D. Gilbert, S. T. Fiske, \& G. Lindzey (Eds.), Handbook of social psychology (Vol. 1, pp. 233-265). New York: McGraw-Hill.

[5] Delhey, J., Newton, K., \& Welzel, C. (2011). How general is trust in “most people”? Solving the radius of trust problem. American Sociological Review, 76(5), 786-807.

[6] Argyris, C., and Scho“n, D. A. 1978. Organizational learning: A theory of action perspective. Reading, MA: Addison-Wesley. 
[7] Barnett, C. K., \& Pratt, M. G. 2000. From threat-rigidity to flexibility-Toward a learning model of autogenic crisis in organizations. Journal of Organizational Change Management, 13: 74-88.

[8] Baumard, P., \& Starbuck, W. H. 2005. Learning from failures: Why it may not happen, Long Range Planning, 38: 281-298.

[9] Campbell, J.L., and O.K. Pedersen: 1996, "Legacies of Change: Transformations of Postcommunist European Economies (Aldine de Gruyter, NY).

[10]Carroll, G.: 1983, “Dynamic analysis of discrete dependent variables: A didactic essay”, Quality and Quantity: A European-American Journal of Methodology, 17: 425-460.

[11]Dacin, T.M., J. Goodstein, and W.R. Scott: 2002, “Institutional Theory and Institutional Change: Introduction to the Special Research Forum”, Academy of Management Journal, 45 (1), 45-57.

[12]DiMaggio, P., and W. Powell: 1991, “Introduction” in W. Powell and P. DiMaggio (eds.), The New Institutionalism in Organizational Analysis:. University of Chicago Press, Chicago), pp. 1-38. 